\title{
Low lung volume alters contractile properties of airway smooth muscle in sheep
}

\author{
M.A. McClean*, M.J. Matheson*, K. McKay, , P.R.A. Johnson`, A-C. Rynell*, A.J. Ammit ${ }^{+}$, J.L. Black \\ N. Berend*
}

Low lung volume alters contractile properties of airway smooth muscle in sheep. M.A. McClean, M.J. Matheson, K. McKay, P.R.A. Johnson, A-C. Rynell, A.J. Ammit, J.L. Black, N. Berend. (C) ERS Journals Ltd 2003.

ABSTRACT: Breathing at volumes lower than functional residual capacity (FRC) can induce changes in nonasthmatic airways consistent with the behaviour of asthmatic airways. This study investigated the chronic effect of breathing at volumes lower than FRC on the contractility of airway smooth muscle and myosin light chain kinase (MLCK) content and activity.

Sheep of three age groups (neonate, adolescent and adult) had their FRC reduced by $\sim 25 \%$ for 4 weeks using a leather corset. Contractile responses to carbachol were then recorded in isolated tracheal strips and bronchial rings. MLCK content and activity were assessed by immunoblotting.

The rate of stress generation increased in the bronchial smooth muscle of both adult and adolescent but not neonatal corseted sheep: adolescent corseted versus control, $65.0 \pm 4.1$ versus $103.4 \pm 7.0 \mathrm{~s}$ (to reach $50 \%$ maximum stress), respectively; and adult corseted versus control, $57.0 \pm 6.4$ versus $93.4 \pm 8.2 \mathrm{~s}$, respectively. This was not due to increases in either bronchial or tracheal smooth muscle amount or MLCK content and activity.

The present results indicate that chronic breathing at low lung volumes increases the rate of stress generation in airway smooth muscle.

Eur Respir J 2003; 22: 50-56.
*Woolcock Institute of Medical Research, Royal North Shore Hospital Campus, ${ }^{\#}$ School of Paediatrics and Child Health, "Dept of Pharmacology and ${ }^{+}$Faculty of Pharmacy, University of Sydney, Sydney and ${ }^{\$}$ Dept of Respiratory Medicine, The Children's Hospital, Westmead, Australia.

Correspondence: N. Berend, Woolcock Institute of Medical Research, Royal North Shore Hospital Campus, Sydney, New South Wales 2065, Australia.

Fax: 61299066931

E-mail: nberend@med.usyd.edu.au

Keywords: Airway smooth muscle, lung volume, myosin light chain kinase

Received: October 302002

Accepted after revision: February 52003

This study was supported by the Asthma Foundation of New South Wales, St Leonards, NSW, Australia and the National Health and Medical Research Council, Canberra, ACT, Australia.
Excessive airway narrowing resulting from airway smooth muscle (ASM) contraction in response to physical and chemical stimuli is a characteristic of asthma. Breathing at volumes lower than functional residual capacity (FRC) can induce changes in nonasthmatic airways that are consistent with the behaviour of asthmatic airways. Animal studies have shown the marked influence of lung volume on ASM function [1-3], and in some clinical situations in which patients chronically breathe at lower lung volumes, this has been suggested as being responsible for changes in airway symptoms. This is the case in obese patients in whom there is an increased prevalence of wheezing [4-6] and airway hyperresponsiveness [7, 8].

The key regulator of the enzymatic pathway involved in smooth muscle contraction is myosin light chain kinase (MLCK), a dedicated protein kinase, with myosin as its only physiological substrate. MLCK regulates smooth muscle contraction by controlling the activity of actomyosin adenosine triphosphatase (ATPase) and in turn the rate of cross-bridge cycling $[9,10]$. In smooth muscle, it has been shown that the activity of actomyosin ATPase can be viewed mechanically as an index of shortening velocity $[11,12]$. A number of physiological studies have been performed using sensitised ASM as a model of asthmatic muscle. These studies have shown that sensitised ASM exhibits increased maximal shortening capacity and increased early shortening velocity $[13,14]$. Further investigations revealed that these observed changes in the contractile

$\overline{\text { For editorial comments see page } 3 .}$ response of ASM were a result of an increase in both the amount and activity of MLCK present in the muscle [15-17].

Another proposed mechanism for the effect of lung volume is ASM plasticity, in which the organisation of the contractile apparatus of the smooth muscle cell is modified to adapt to changes in muscle length, thus optimising contractility and force generation. The stretch or lengthening of ASM during tidal breathing and deep inspirations (DIs) may cause reorganisation of the contractile apparatus thereby reducing the responsiveness of the airway [18], i.e. if the smooth muscle is not lengthened intermittently, force generation increases and the muscle shortens more [19-21].

In the present study, the objective was to investigate the effect of chronically breathing at volumes lower than FRC on the contractility of ASM from sheep of various ages, as both the amount and function of ASM may be age-related. By determining whether the content and activity of MLCK were affected by breathing at low lung volumes, a possible mechanism for any changes in ASM contractility was investigated.

\section{Materials and methods}

\section{Study groups}

Three age groups of corseted and control cross-bred sheep were studied: neonates (aged 5-7 days), adolescents (aged 3 months) and adults (aged $>12$ months). All six treatment 
groups contained six sheep, except for the neonatal control group, which contained five. The animals were housed in individual pens and given food and water ad libitum. The protocol was approved by the University of Technology, Sydney/Royal North Shore Hospital (Sydney, Australia) Animal Care and Ethics Committee.

\section{Experimental protocol}

The sheep were anaesthetised using thiopental (Pentothal $\mathbb{R}$ 5\%; Abbott Australasia, Kurnell, NSW, Australia; $20 \mathrm{mg} \cdot \mathrm{kg}$ body weight ${ }^{-1}$ i.v.) and intubated with an endotracheal tube. Suxamethonium (AstraZeneca, North Ryde, NSW, Australia; $1 \mathrm{mg} \cdot \mathrm{kg}$ body weight ${ }^{-1} i$.v.) was used to paralyse spontaneous respiration and the sheep were ventilated with a Bird ventiflator $(500-600 \mathrm{~mL}$ tidal volume in adult group). FRC was determined using the helium-dilution technique. This involves inflating the lungs to total lung capacity with $10 \%$ helium in air via the endotracheal tube in a closed system that allows the helium to mix evenly with the air already present in the lungs. A sample of the air in the lungs is then taken and the helium content measured using a Morgan helium analyser md2-FRC (P.K. Morgan, Chatham, UK). Six inflations provided a nadir in the helium concentration. The sheep that were corseted had a specially designed leather corset placed around their chest, which was adjusted to reduce their FRC by $\sim 25 \%$. The control sheep underwent the same protocol of anaesthesia and lung volume measurement without being corseted. The sheep were then allowed to regain consciousness and return to their normal activities. Lung volume was remeasured and the corsets adjusted weekly for 4 weeks to maintain the $25 \%$ reduction in FRC. After 4 weeks, the sheep were sacrificed with an overdose of intravenous pentobarbital (Nembutal; Boehringer Ingelheim, Artarmon, NSW, Australia), and the lungs and trachea distal to the larynx were removed and placed on ice for in vitro use.

\section{Measurement of deep inspiration}

In the adult and adolescent groups, inductance plethysmograph transducer bands, which consist of insulated wire sewn on to elastic material, were placed around the chest and abdomen of both corseted and control sheep. The bands were then attached to a Stand Alone Medical Monitoring Interface (Vitalog Monitoring Inc., Redwood City, CA, USA) connected to a Yew Type 3057 Portable Recorder (Yokogawa Hokushin Electric, Tokyo, Japan). The breathing pattern of the sheep was recorded over $15 \mathrm{~min}$ and the number of DIs counted. A DI was defined as an inspiration of 1.5 times the baseline tidal volume.

In two adult sheep, one corseted and one control, inductance plethysmography was performed quantitatively. Here, the inductance plethysmograph bands were calibrated using a fixed volume of air syringed into the anaesthetised, paralysed and ventilated sheep.

\section{Blood gases}

A 16-gauge catheter with an attached tap was inserted into the carotid artery of one corseted and one control adult sheep. For $48 \mathrm{~h}$ at 2-h intervals, the catheter was flushed with heparinised saline and $1 \mathrm{~mL}$ arterial blood drawn into a heparinised syringe. Arterial carbon dioxide $\left(\mathrm{Pa}, \mathrm{CO}_{2}\right)$ and oxygen $\left(\mathrm{Pa}, \mathrm{O}_{2}\right)$ tensions were measured using an ABL System 625 (Radiometer, Copenhagen, Denmark).

\section{In vitro contractility studies}

Midtracheal segments were obtained by cutting the trachea transversely to obtain two 3-mm-wide strips, which were prepared by removing the cartilage from these segments. Two bronchial rings $(3-4 \mathrm{~mm}$ in length and $4-5 \mathrm{~mm}$ internal diameter) were obtained from the same level of each right lung. The tracheal strips and bronchial rings were mounted on stainless steel hooks in jacketed tissue baths, incubated at $37^{\circ} \mathrm{C}$ in Krebs-Henseleit solution and aerated continuously with carbogen. All tissues were equilibrated under a preload of $25 \mathrm{mg}$ for $1 \mathrm{~h}$, during which time the bath solution was flushed at 15-min intervals. After equilibration, contractile responses to $1 \mu \mathrm{M}$ acetylcholine $(\mathrm{ACh})$ were elicited from each tissue. These contractile responses were measured using a Grass FTO3 isometric force transducer (Grass Instruments, Quincy, MA, USA) coupled to an analogue-to-digital recording device (MacLab ${ }^{\mathrm{TM}}$; AD Instruments, Sydney, Australia). The maximum response to ACh in milligrams of generated force was recorded and the tissues were then washed until baseline level was reattained. The preload was then increased by $25-\mathrm{mg}$ increments, the muscle restimulated with $1 \mu \mathrm{M}$ $\mathrm{ACh}$, the force generated recorded and the process continued until the optimal preload (Lo) was found (i.e. the load at which the response to $1 \mu \mathrm{M}$ ACh is maximal). The tissues were allowed to settle for $1 \mathrm{~h}$ at Lo. The response to $10 \mu \mathrm{M}$ carbachol (Sigma Chemical Company, Castle Hill, NSW, Australia), used for its direct action on ASM, was then elicited in each tissue. Changes in force were measured at 2-s intervals for the first $3 \mathrm{~min}$ and then at 1-min intervals until 5 min had elapsed. The tissues were then washed three times, removed from the tissue baths, placed under Lo and fixed in $10 \%$ neutral-buffered formalin.

\section{Morphometry}

Tissues were removed from formalin, processed and embedded in paraffin. Sections were cut and stained with Masson trichrome stain. Morphometry was performed on nine sections from each bronchial ring and tracheal strip blind to both age and treatment. The microscopic image of the section was projected and the following traced using a digitiser and Phoenix Enhanced Video BIOS software. For the bronchial rings, the airway internal perimeter, the internal and external perimeter of the muscle (subtracted to give total smooth muscle area) and the internal and external perimeter of the cartilage (subtracted to give total cartilage area) were measured. The square root of each wall area was taken and divided by the length of the internal perimeter to enable comparisons between airways [22]. For the tracheal strips, the length of the strip and total area were measured.

\section{Airway smooth muscle preparation for biochemical analysis}

Tracheal smooth muscle samples were obtained by removing the cartilage and cutting the muscle at $3-\mathrm{mm}$ intervals. The bronchi were removed from the surrounding lung parenchyma and opened by cutting through the cartilage. The epithelial layer was removed manually and the underlying smooth muscle bundles were collected using forceps. Both tracheal and bronchial smooth muscle were stored at $-70^{\circ} \mathrm{C}$ for later biochemical analysis.

Unless otherwise stated, all chemicals used in the present study were purchased from either Sigma Chemical Company or Bio-Rad Laboratories (Regents Park, NSW, Australia). 


\section{Measurement of myosin light chain kinase content}

MLCK content was measured in ASM from corseted and control adult ( $n=6$ in both groups) and adolescent $(n=3$ in both groups), but not neonatal, sheep using the method employed by AMмIT et al. [23]. Following protein separation by gel electrophoresis, proteins were transferred to Immun-Blot $\mathbb{R}$ polyvinylidene difluoride (PVDF) membrane (Bio-Rad Laboratories) for $1 \mathrm{~h}$ at $100 \mathrm{~V}$. After the transfer, the PDVF membrane was subjected to immunoblotting using a 1:2,000 dilution of mouse anti-MLCK monoclonal antibody (immunoglobulin ( $\mathrm{Ig}) \mathrm{G}_{2 \mathrm{~b}}$, clone K36), followed by a 1:1,000 dilution of alkaline phosphatase-conjugated antimouse polyvalent antibody (IgG, IgA and IgM). The MLCK bands were detected following incubation of the PDVF membrane in a chromogen solution $(0.1 \mathrm{M}$ tris-(hydroxymethyl)-aminomethane (Tris), $\left.5 \mathrm{mM} \mathrm{MgCl}_{2} \cdot 6 \mathrm{H}_{2} \mathrm{O}, 100 \mathrm{mM} \mathrm{NaCl}, \mathrm{pH} 9.5\right)$ containing $0.5 \%$ 5-bromo-4-chloro-3-indolyl phosphate ( $p$-toludine salt) and $0.5 \%$ nitroblue tetrazolium. MLCK content was semiquantified using scanning densitometry.

\section{Measurement of $20 \mathrm{kDa}$ myosin light chain phosphorylation}

In order to measure the activity of MLCK in ASM from corseted and control adult ( $\mathrm{n}=6$ in both groups) and adolescent ( $n=3$ in both groups) sheep, a modified method of nondenaturing polyacrylamide gel electrophoresis was used to separate monophosphorylated (MLC20-P) and unphosphorylated (MLC20) $20 \mathrm{kDa}$ myosin light chain [24]. Following electrophoresis, the separated proteins were transferred to nitrocellulose (Bio-Rad Laboratories; $0.45 \mu \mathrm{m}$ ) for $3 \mathrm{~h}$ at $1,500 \mathrm{~mA}$. After transfer, the nitrocellulose was subjected to immunoblotting with a 1:500 dilution of mouse anti-MLC20 monoclonal antibody (IgM, clone MY-21) followed by a 1:3,000 dilution of antimouse polyvalent $\operatorname{Ig}(\operatorname{IgG}, \operatorname{IgA}$ and IgM) antibody conjugated to horseradish peroxidase. The unphosphorylated and monophosphorylated MLC20 bands were detected using electrochemoluminscence (Amersham Pharmacia Biotech, Castle Hill, NSW, Australia) and the chemolumigrams were developed using Hyperfilm (Amersham Pharmacia Biotech). In order to semiquantify phosphorylation of MLC20, scanning densitometry was performed. The ratio of MLC20-P to total MLC20 present in the muscle was used as an index of MLCK activity.

\section{Statistical analysis}

Data are presented as mean \pm SEM unless otherwise stated. The relationship between stress ( $\mathrm{mg}$ force $\cdot \mathrm{mm}$ smooth muscle ${ }^{-2}$ ) and time (s) was determined using the t-test at either three time points or three levels of stress; unpaired t-tests were also used to compare MLCK content and activity between the control and corseted groups of adolescent and adult sheep. A p-value of $<0.05$ was considered significant.

\section{Results}

\section{Maintenance of low lung volume}

Lung volume was remeasured at weekly intervals to ensure a constant reduction in FRC of $\sim 25 \%$ throughout the 4-week period (table 1). The neonatal group was rapidly growing, with the control sheep gaining $123.2 \mathrm{~mL}$ in FRC over the 4-week period. The corseted neonates did not show the same
Table 1. - Functional residual capacity (FRC) at baseline and 4 weeks in control and corseted neonatal, adolescent and adult sheep

\begin{tabular}{lrcr}
\hline & \multicolumn{3}{c}{ FRC mL } \\
\cline { 2 - 4 } & Baseline & Baseline corseted & 4 weeks \\
\hline Neonates & & & \\
$\quad$ Control & $84.5 \pm 35.5$ & & $207.7 \pm 29.0$ \\
$\quad$ Corseted & $136.4 \pm 40.6$ & $100.9 \pm 35.8$ & $144.1 \pm 33.4$ \\
Adolescents & & & \\
$\quad$ Control & $353.8 \pm 49.4$ & & $299.1 \pm 34.5$ \\
$\quad$ Corseted & $380.9 \pm 47.8$ & $279.8 \pm 36.8$ & $305.6 \pm 29.7$ \\
Adults & & & $1100.9 \pm 43.8$ \\
$\quad$ Control & $1033.5 \pm 73.6$ & & $705.0 \pm 62.7$ \\
$\quad$ Corseted & $959.6 \pm 79.6$ & $688.3 \pm 49.6$ & \\
\hline
\end{tabular}

Data are presented as mean \pm SEM $(n=6$ for all except neonatal control group $(n=5))$.

increase in FRC as recorded in the control group. In the adolescent and adult age groups, no significant difference between FRC from the beginning of the corseting to the end of the 4-week period was noted, indicating that the reduction in lung volume was maintained over the 4 weeks.

\section{Deep inspirations}

In the adolescent sheep, application of the corset resulted in a significant increase in the number of DIs taken at week 1 $(19.3 \pm 2.6)$ compared with control $\left(9.7 \pm 1.5 \mathrm{DIs} \cdot 15 \mathrm{~min}^{-1}\right)$. At baseline and weeks 2, 3 and 4, there was no significant difference in the number of DIs recorded in the corseted $\left(14.0 \pm 2.9,11.3 \pm 1.2\right.$ and $\left.11.0 \pm 2.1 \mathrm{DIs} \cdot 15 \mathrm{~min}^{-1}\right)$ and control $\left(16.7 \pm 2.0,12.7 \pm 1.8\right.$ and $\left.12.3 \pm 1.5 \mathrm{DIs} \cdot 15 \mathrm{~min}^{-1}\right)$ adolescent sheep.

In the adult sheep, the reduction in lung volume did not affect the number of DIs taken at baseline and weeks 1, 2, 3 and 4 by the corseted $(17.7 \pm 6.2,18.0 \pm 4.6,9.0 \pm 1.8,16.2 \pm 2.4$ and $\left.20 \pm 6.0 \mathrm{DIs} \cdot 15 \mathrm{~min}^{-1}\right)$ and control $(22.0 \pm 3.6,16.2 \pm 1.9$, $13.0 \pm 1.9,16.3 \pm 2.0$ and $\left.19.8 \pm 5.0 \mathrm{DIs} \cdot 15 \mathrm{~min}^{-1}\right)$ sheep. Quantitative inductive plethysmography on two adult sheep showed no difference in tidal volume between corseted and control sheep.

It was also noted in the corseted sheep of both age groups that DIs resulted from abdominal and not chest movement.

The number of DIs was not measured in the neonatal group as the inductance plethysmograph transducer bands were too large for the sheep.

\section{Blood gases}

In adult corseted sheep, $P \mathrm{a}, \mathrm{CO}_{2}(5.11 \pm 0.17 \mathrm{kPa}(38.4 \pm$ $1.3 \mathrm{mmHg}$ )) was not elevated, nor was there a corresponding fall in $\mathrm{Pa}_{2} \mathrm{O}_{2}(13.9 \pm 0.23 \mathrm{kPa}(104.6 \pm 1.7 \mathrm{mmHg}))$. Levels in adult control sheep were $5.69 \pm 0.13 \mathrm{kPa}(42.8 \pm 1.0 \mathrm{mmHg})$ and $15.1 \pm 0.23 \mathrm{kPa}(113.2 \pm 1.7 \mathrm{mmHg})$, respectively.

\section{Smooth muscle contractility in vitro}

The contractile response of tracheal smooth muscle was unaffected by the reduction in lung volume induced by the corset in all age groups. Figure 1 illustrates the stress generated by ASM in response to $10 \mu \mathrm{M}$ carbachol as a percentage of the maximum stress attained in all three age groups. 

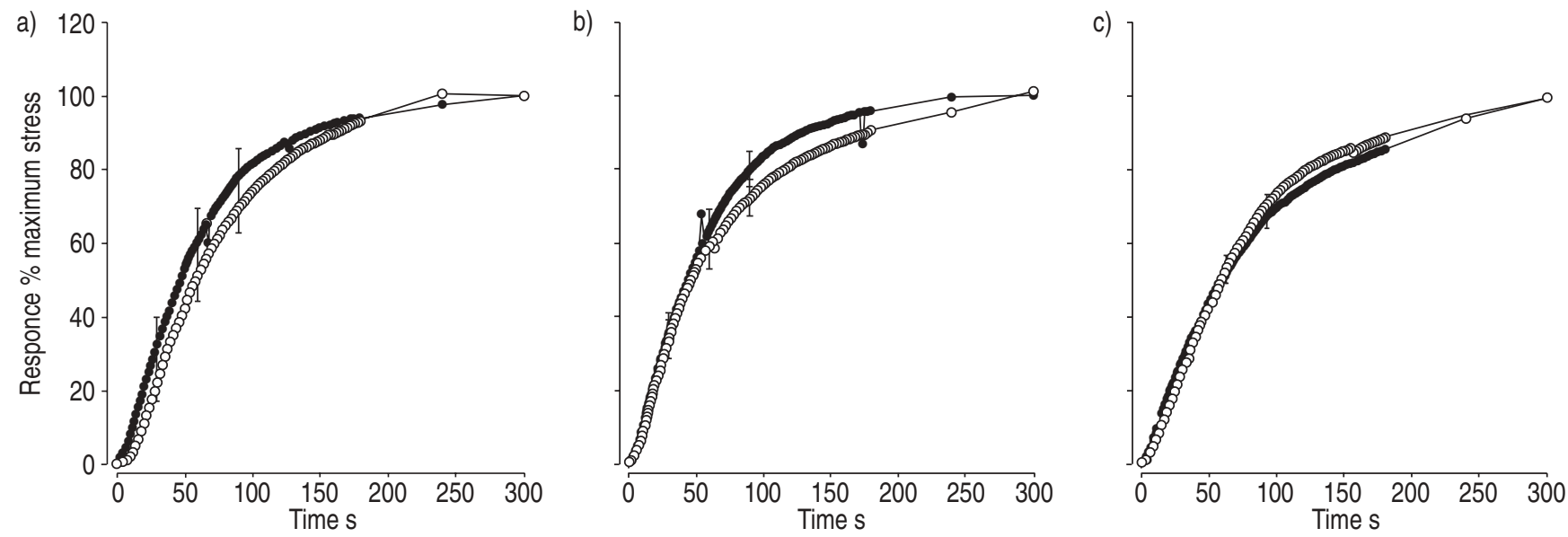

Fig. 1. - Contractile response of tracheal smooth muscle with time in a) neonatal, b) adolescent, and c) adult control ( $\bullet)$ and corseted ( $\bigcirc)$ sheep. Vertical bars represent SEM ( $\mathrm{n}=6$ for all except neonatal control $\mathrm{n}=5)$.
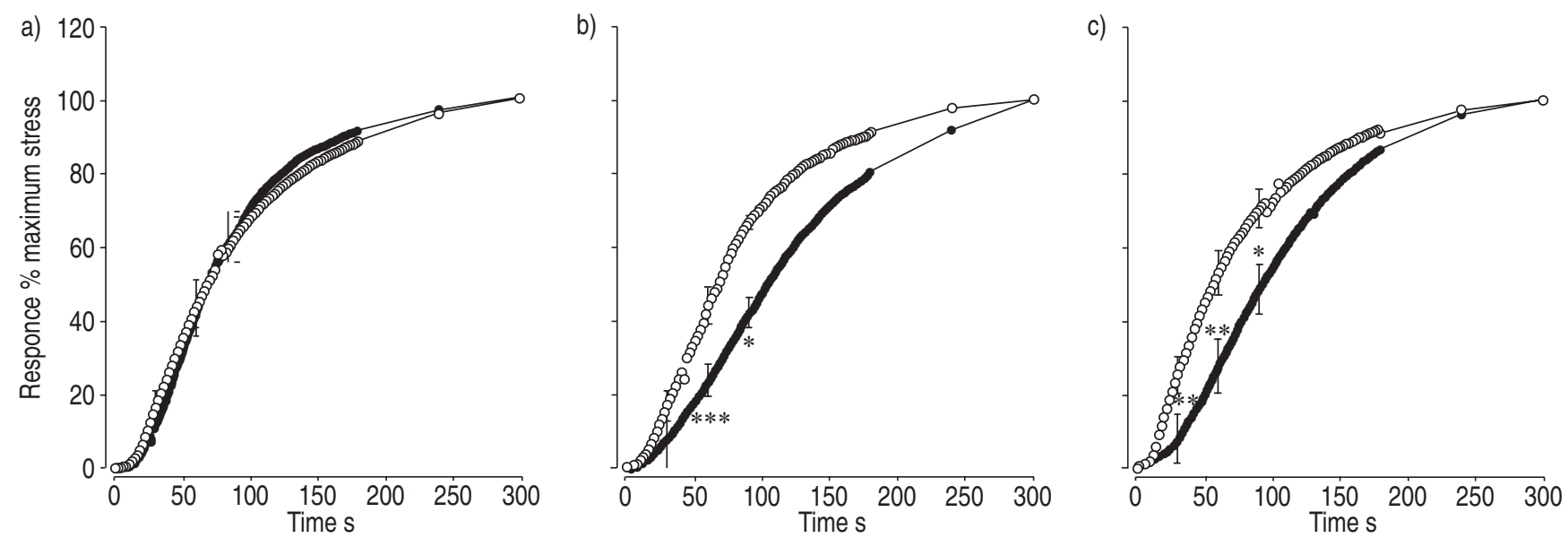

Fig. 2. - Contractile response of bronchial smooth muscle with time in a) neonatal, b) adolescent, and c) adult control $(\bullet)$ and corseted $(\bigcirc)$ sheep. Vertical bars represent SEM ( $\mathrm{n}=6$ for all). $*$ : $\mathrm{p}<0.05, * *: \mathrm{p}<0.01, * * *: \mathrm{p}<0.001$ versus control sheep.

The bronchial smooth muscle contractile response in neonates was also unaffected by the reduction in lung volume, as shown in figure $2 \mathrm{a}$.

In adolescent and adult sheep, a reduction in lung volume produced a significant effect on the contractile response of bronchial smooth muscle at 30,60 and $90 \mathrm{~s}$. This is shown in figure $2 b$ and $c$, which depicts the stress of the muscle as a percentage of the maximum stress attained. As illustrated in figure 3 , the time taken to reach 25,50 and $75 \%$ of maximum stress is significantly less in corseted sheep than in control sheep.

\section{Morphometry}

The amount of bronchial smooth muscle and cartilage and tracheal smooth muscle did not differ significantly between the control and corseted neonatal, adolescent and adult sheep (table 2).

\section{Measurement of myosin light chain kinase content}

The amount of MLCK present in the bronchial smooth muscle of the control and corseted adolescent sheep and adult, as shown in figure 4, was not significantly different.

\section{Measurement of $20 \mathrm{kDa}$ myosin light chain phosphorylation}

Figure 5 shows the electrophoretic pattern of sheep bronchial smooth muscle; both the unphosphorylated MLC20 and monophosphorylated MLC20-P bands are clearly visible.

The activity of MLCK in bronchial smooth muscle from adolescent and adult control and corseted sheep did not differ, as shown in figure 6 .

\section{Discussion}

Airway hyperresponsiveness with excessive airway narrowing is a characteristic of asthma. Clinical observations have indicated that breathing at low lung volumes and the effects of a DI during bronchial challenge influence airway narrowing. Clearly, changes in lung volume are important in regulating airway reactivity, and presumably this regulation results from the stretch (or lack of stretch) of ASM that occurs following lung volume alteration. It has been hypothesised that the most important determinant of airway hyperresponsiveness is the relationship between shortening velocity and cyclical length changes in ASM during tidal breathing [24, 25]. Studies have shown that, in isolated tracheal and bronchial segments, the contractility of the smooth muscle is altered by changes in 

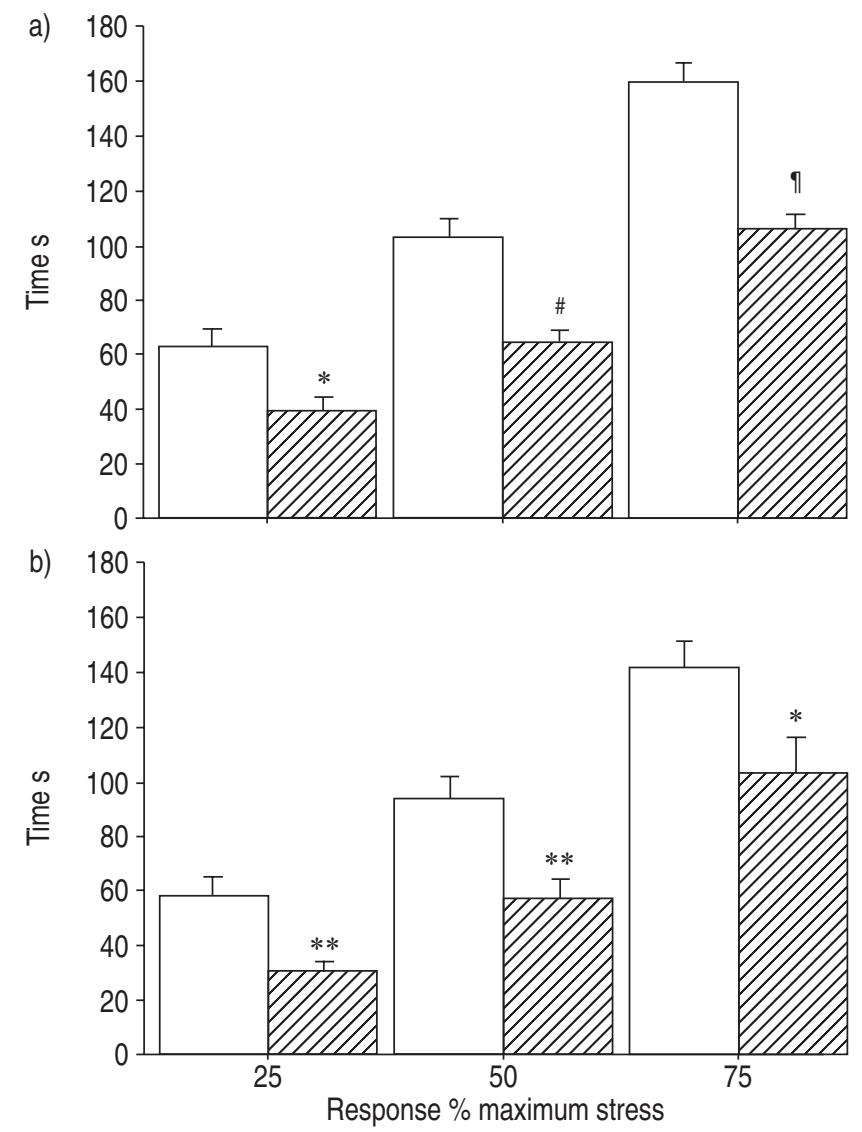

Fig. 3. - Time taken for bronchial smooth muscle to attain 25, 50 and $75 \%$ of maximum stress in a) adolescent, and b) adult control ( $\square$ ) and corseted $(\mathbb{Z})$ sheep. Data are presented as mean \pm SEM. *: $\mathrm{p}<0.05$, ${ }^{* *}: \mathrm{p}<0.01,{ }^{\#}: \mathrm{p}<0.005,{ }^{\circ}: \mathrm{p}<0.0005$ versus control sheep ( $\mathrm{n}=6$ for all).

lung volume or muscle length [26-28]. In the present study, breathing at low lung volumes resulted in an increased rate of stress generation in response to carbachol. This was seen in both the adult and adolescent groups, whereas no alteration in ASM contractile response was noted in the neonatal group. The main possible explanations of these changes are alterations in activation of actomyosin ATPase, the contractile apparatus and amount of ASM.

The increase in stress generation that was observed in the present study could be a result of changes in the enzymatic pathways responsible for ASM contraction. Any increase in

Table 2.-Morphometry

\begin{tabular}{cccc}
\hline & \multicolumn{2}{c}{ Bronchi } & $\begin{array}{c}\text { Tracheal smooth } \\
\text { muscle mm }\end{array}$ \\
\cline { 2 - 3 } & Smooth muscle mm & Cartilage mm & \\
\hline Neonates & & & \\
$\quad$ Control & $0.08 \pm 0.002$ & $0.22 \pm 0.02$ & $18.3 \pm 5.8$ \\
$\begin{array}{c}\text { Corseted } \\
\text { Adolescents }\end{array}$ & $0.08 \pm 0.003$ & $0.24 \pm 0.02$ & $17.5 \pm 5.2$ \\
$\quad$ Control & $0.09 \pm 0.005$ & $0.22 \pm 0.11$ & $41.7 \pm 19.3$ \\
$\quad$ Corseted & $0.07 \pm 0.004$ & $0.20 \pm 0.005$ & $52.3 \pm 8.6$ \\
Adults & $0.07 \pm 0.003$ & $0.21 \pm 0.007$ & $52.5 \pm 15.8$ \\
$\quad$ Control & $0.08 \pm 0.008$ & $0.23 \pm 0.03$ & $72.2 \pm 16.5$ \\
\hline Corseted & $0.08 \pm 0$ \\
\hline
\end{tabular}

Data are presented as mean \pm SEM ( $\mathrm{n}=6$ for all except neonatal control group $(\mathrm{n}=5)$ ). The square root of each wall area was taken and divided by the length of the internal perimeter to enable comparisons between airways [22].

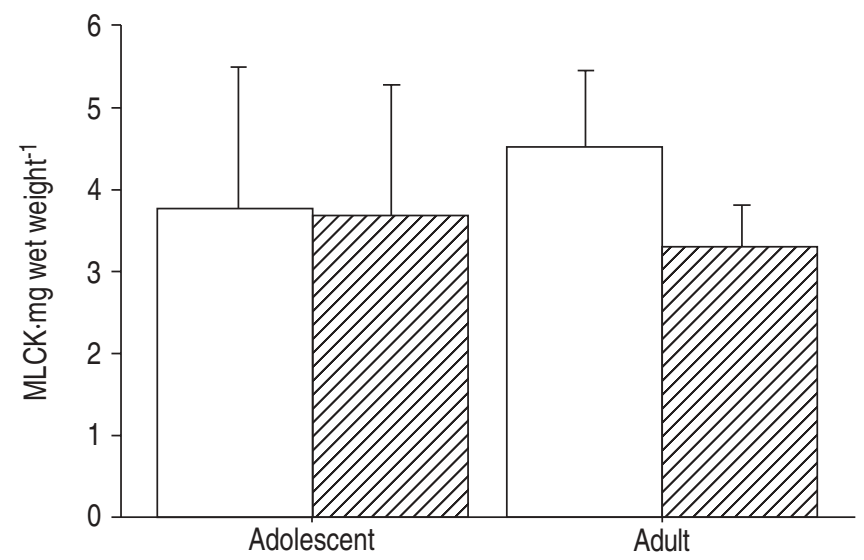

Fig. 4. - Myosin light chain kinase (MLCK) content in bronchial smooth muscle from adolescent $(\mathrm{n}=3)$ and adult $(\mathrm{n}=6)$ control $(\square)$ and corseted $(\mathbb{Z})$ sheep. Data are presented as mean \pm SEM.

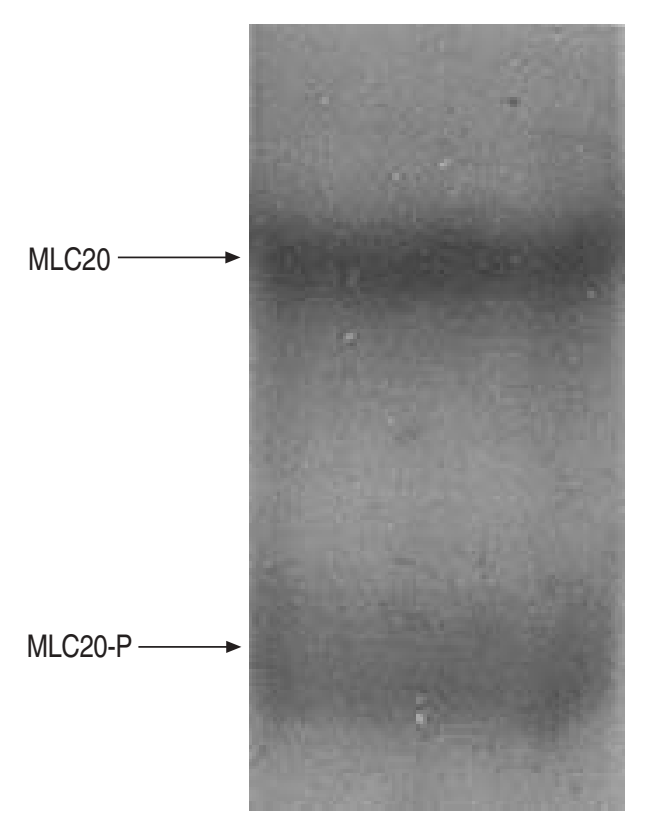

Fig. 5.-Immunoblot showing phosphorylation of $20 \mathrm{kDa}$ myosin light chain (MLC20) in bronchial smooth muscle from sheep. The monophosphorylated (MLC20-P) and unphosphorylated MLC20 bands are clearly visible.

the activities of both MLCK and actomyosin ATPase would result in an increase in the shortening velocity, as shown by STEPHENS and co-workers [15-17]. In the present study, the possibility of a change in the content and activity of MLCK being the mechanism responsible for the increased rate of stress generation seen in the corseted sheep of both the adolescent and adult groups was discounted. However, it is possible that the differences are due to signalling events upstream of MLCK phosphorylation. This possibility was not addressed in the present study.

The biochemical protocols utilised in the present study were the same as those employed by AMmiт et al. [23]. These protocols have been successfully used by a number of investigators for both ASM and other smooth muscle preparations [15-17, 29, 30] and are appropriate for the current studies. It seems unlikely that methodological issues or tissue handling/ selection could be responsible for the lack of observed differences between the control and corseted sheep.

The elimination of a change in the content and activity of 


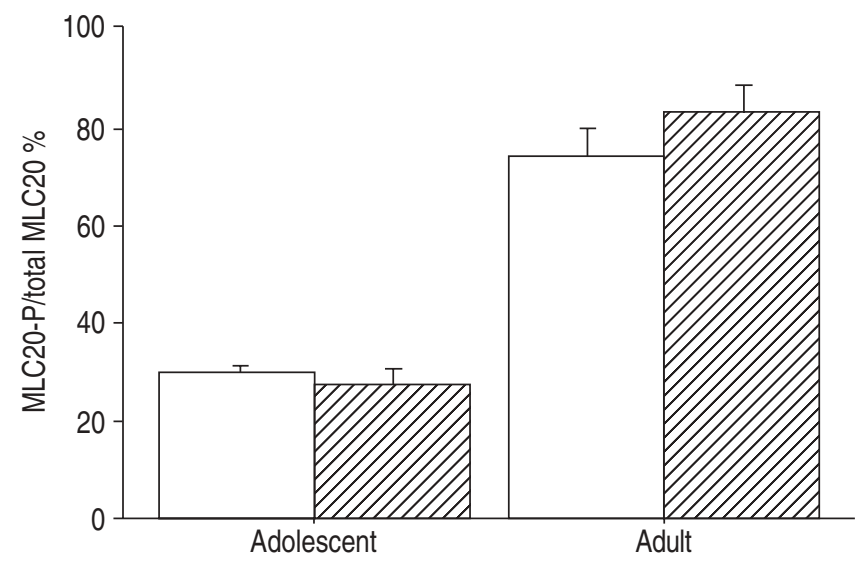

Fig. 6.-Myosin light chain kinase activity in bronchi from adolescent $(\mathrm{n}=3)$ and adult ( $\mathrm{n}=5$ control, $\mathrm{n}=6$ corseted) control $(\square)$ and corseted $(\mathbb{Z})$ sheep. Data are presented as mean \pm SEM. MLC20: $20 \mathrm{kDa}$ myosin light chain; MLC20-P: monophosphorylated MLC20.

MLCK as a possible mechanism for the increased rate of stress generation, raises the question of what other mechanisms could be responsible for the observed results. One potential mechanism that must be considered is ASM plasticity. This means that ASM cells have the ability to alter the organisation of their contractile apparatus in response to changes in cell shape caused by various physical and chemical stimuli [20]. When smooth muscle is stimulated at different muscle lengths, differences in muscle stiffness and responsiveness result. If the muscle is activated at a short length, the contractile apparatus is rearranged to produce a shorter thicker filament array, and a stiffer less distensible muscle results. If the muscle is activated at a longer length, the opposite occurs [20].

During tidal breathing, ASM undergoes cycles of lengthening and shortening, in which the contractile apparatus lengthens and shortens, modulating airway tone and responsiveness [28]. In the present study, lung volume was reduced by the corset and this reduced volume was maintained over a 4-week period. It is possible that the contractile apparatus of the bronchial smooth muscle cells was reorganised due to the low lung volumes induced by the corset. The maintenance of this reduction in lung volume over a fixed time period allowed the bronchial smooth muscle to be maintained at a shorter length than normal, resulting in a stiffer muscle, thus lessening the muscle's contractility. The lengthening or stretching of ASM that occurs during a DI may reorganise the contractile apparatus of the ASM cells and reduce airway responsiveness [18]. If DIs are prevented, the muscle is not lengthened intermittently, and, as a result, the muscle shortens more [19-21]. As the corset did not prevent DIs in the sheep, it is possible that the effect of the DIs was somehow diminished. As noted, the DIs recorded in the corseted sheep resulted from abdominal rather than chest breathing movement. A DI may have had the effect of longitudinal rather than transverse stretching of at least the more proximal axial airways.

It is also possible that, although there was no difference in the area of smooth muscle in the bronchi between the corseted and control sheep, a change occurred in the series elastic element in the smooth muscle bundles. No quantification of this potential contribution to the observed differences in the rate of stress generation was attempted. It has been shown that an increased shortening velocity of the contractile element in series with the series elastic component is partly responsible for an increased rate of force generation following length changes. The contractile element's shortening velocity is proportional to the number of contractile units in series.
Thus, an increased rate of force generation may result from the presence of more and shorter contractile units in the ASM cell [31]. SEOW et al. [32] speculated that during activation the myosin filaments are reformed (more myosin filaments are added in series in the smooth muscle cell) and lengthening of the muscle results in a series-to-parallel transition in the filament lattice. Thus, the present results are consistent with the findings of SEOW et al. [32].

No differences in the contractile response were observed in the neonatal group. Although the reduction in lung volume in this group was not as consistent as in the other groups, this is an unlikely reason for the differences between the neonatal group and other groups. It is possible that neonatal ASM exhibits different responses to physical deformation, and, in addition, there is evidence of an ontogenic effect on airway responsiveness in sheep [33].

The contractile response of the tracheal smooth muscle in all three groups did not change. This is the expected outcome, as the extrapleural trachea would not undergo a change in dimension with the lung volume change induced by the corset, and therefore it serves as a negative control. This demonstrates that the changes seen in the bronchi were related directly to the physical changes in airway dimensions produced by reduction in FRC and not to any secondary systemic effects.

Isometric measurements were employed in the present study as ASM hyperresponsiveness is more likely to be detected by this method. If the responsiveness of ASM is due to the amount of smooth muscle present in the preparation, then isometric measurements allow better correlation between the two [34].

In the present study, the aim was to examine the effects of chronic breathing at low lung volumes on the contractility of ASM. It was decided to study these effects in isolated airway preparations to preclude the complication of changes in lung elastic recoil, which would be induced by chest strapping, on measurements of airway hyperresponsiveness.

The present study suggests that tidal breathing at low lung volumes for 4 weeks results in an increased rate of stress generation in bronchial smooth muscle. The duration of maintenance of this effect is unknown, but it is clearly not transient as the results were obtained after excision of muscle and maintained during the establishment of optimal preload. The finding, for the first time, of an alteration in the contractile properties of airway smooth muscle with chronic lung volume reduction provides a theoretical basis for the change in airway responsiveness demonstrated in obese subjects. The relationship between the rate of stress generation in vitro and airway hyperresponsiveness in vivo is the subject of current investigations.

\footnotetext{
Acknowledgements. The authors would like to thank R. Kearns and the staff of Wellcome Laboratories (Royal North Shore Hospital, Sydney, Australia) for their care and assistance with the sheep during the present study, and R. Davey and R. Harvie of the Bill Walsh Cancer Research Laboratory (Royal North Shore Hospital) for the use of their equipment for the quantification of myosin light chain kinase.
}

\section{References}

1. Hahn NL, Graf PD, Nadel JA. Effect of vagal tone on airway diameters and lung volume in anesthetized dogs. J Appl Physiol 1976; 41: 581-589.

2. Bellofiore S, Eidelman DH, Macklem PT, Martin JG. Effects 
of elastance-induced emphysema on airway responsiveness to methacholine in rats. J Appl Physiol 1989; 66: 606-612.

3. Robatto FM, Simard S, Orana FI, Macklem PT. Effect of lung volume on plateau response of airways and tissue to methacholine in dogs. J Appl Physiol 1992; 73: 1908-1913.

4. Ray CS, Sue DY, Bray G, Hansen JE, Wasserman K. Effects of obesity on respiratory function. Am Rev Respir Dis 1983; 128: 501-506.

5. Pelosi P, Croci M, Ravagnan I, et al. Respiratory system mechanics in sedated, paralysed, morbidly obese patients. J Appl Physiol 1997; 82: 811-818.

6. Shaheen SO. Obesity and asthma: cause for concern? Clin Exp Allergy 1999; 29: 291-293.

7. Litonjua AA, Sparrow D, Celedon JC, DeMolles D, Weiss ST. Association of body mass index with the development of methacholine airway hyperresponsiveness in men: the Normative Aging Study. Thorax 2002; 57: 581-585.

8. Chinn S, Jarvis D, Burney P. Relation of bronchial responsiveness to body mass index in the ECRHS. Thorax 2002; 57 : $1028-1033$.

9. Walsh MP. Calcium-dependent mechanisms of regulation of smooth muscle contraction. Biochem Cell Biol 1991; 69: 771800.

10. Dillion PF, Aksoy MO, Driska SP, Murphy RA. Myosin phosphorylation and cross-bridge cycle in arterial smooth muscle. Science 1981; 211: 495-497.

11. Fredberg JJ, Jones KA, Nathan M, et al. Friction in airway smooth muscle: mechanism, latch and implication in asthma. J Appl Physiol 1996; 81: 2703-2712.

12. Bárány M. ATPase activity of myosin correlated with speed of muscle shortening. J Gen Physiol 1967; 50: 197-218.

13. Jiang H, Rao K, Halayko AJ, Kepron W, Stephens NL. Bronchial smooth muscle mechanics of a canine model of allergic airway hyperesponsiveness. J Appl Physiol 1992; 72: $39-45$.

14. Antonissen LA, Mitchell RW, Kroeger EA, Kepron W, Tse KS, Stephens NL. Mechanical alterations of airway smooth muscle in canine asthmatic model. J Appl Physiol 1979; 46: 681-687.

15. Jiang H, Rao K, Halayko AJ, Liu X, Stephens NL. Ragweed sensitisation-induced increase of myosin light chain kinase content in canine airway smooth muscle. Am J Respir Cell Mol Biol 1992; 7: 567-573.

16. Jiang H, Rao K, Liu X, Halayko AJ, Liu G, Stephens NL. Early changes in airway smooth muscle hyperresponsiveness. Can J Physiol Pharmacol 1994; 72: 1440-1447.

17. Liu X, Halayko AJ, Liu G, Rao K, Jiang H, Stephens NL. Myosin light chain phosphatase activity in ragweed pollensensitised canine tracheal smooth muscle. Am J Respir Cell Mol Biol 1994; 11: 676-681.

18. Gunst SJ, Shen X, Ramchandani R, Tepper RS. Bronchoprotective and bronchodilatory effects of deep inspiration in rabbits subjected to bronchial challenge. J Appl Physiol 2001; 95: 2511-2516.

19. Gunst SJ, Meiss RA, Wu MF, Rowe M. Mechanisms for the mechanical plasticity of tracheal smooth muscle. $\mathrm{Am} \mathrm{J}$ Physiol 1995; 268: C1267-C1276.

20. Gunst SJ, Wu MF. Plasticity of airway smooth muscle stiffness and extensibility: role of length-adaptive mechanisms. J Appl Physiol 2001; 90: 741-749.

21. Pratusevich VR, Seow CY, Ford LE. Plasticity of canine airway smooth muscle. J Gen Physiol 1995; 105: 73-94.

22. James AL, Hogg JC, Dunn LA, Paré PD. The use of internal perimeter to compare airway size and to calculate smooth muscle shortening. Am Rev Respir Dis 1988; 138: 136-139.

23. Ammit AJ, Armour CL, Black JL. Smooth muscle myosin light chain kinase content is increased in human sensitised airways. Am J Respir Crit Care Med 2000; 161: 257-263.

24. Fredberg JJ, Inouye DS, Mijailovich SM, Butler JP Perturbed equilibrium of myosin binding in airway smooth muscle and its implications in bronchospasm. Am J Respir Crit Care Med 1999; 159: 959-967.

25. Solway J, Fredberg JJ. Perhaps airway smooth muscle dysfunction contributes to asthmatic bronchial hyperresponsiveness after all. Am J Respir Cell Mol Biol 1997; 17: 144 146.

26. Fredberg JJ, Inouye D, Miller B, et al. Airway smooth muscle, tidal stretches and dynamically determined contractile states. Am J Respir Crit Care Med 1997; 156: 1752-1759.

27. Gunst SJ. Contractile force of canine airway smooth muscle during cyclical length changes. $J$ Appl Physiol 1983; 55: 759769 .

28. Shen X, Wu MF, Tepper RS, Gunst SJ. Mechanisms for the mechanical response of airway smooth muscle to length oscillation. J Appl Physiol 1997; 83: 731-738.

29. Liu X, Shao Q, Dhalla NS. Myosin light chain phosphorylation in cardial hypertrophy and failure due to myocardial infarction. J Mol Cell Cardiol 1995; 27: 2613-2621.

30. Liu X, Takeda N, Dhalla NS. Myosin light-chain phosphorylation in diabetic cardiomyopathy in rats. Metabolism 1997; 46: 71-75

31. Kuo K-H, Wang L, Paré PD, Ford LE, Seow CY. Myosin thick filament lability induced by mechanical strain in airway smooth muscle. J Appl Physiol 2001; 90: 1811-1816.

32. Seow CY, Pratusevich VR, Ford LE. Series-to-parallel transition in the filament lattice of airway smooth muscle. J Appl Physiol 2000; 89: 869-876.

33. Saunder RA, McNicol KJ, Stecenko AA. Effect of age on lung mechanics and airway reactivity in lambs. $J$ Appl Physiol 1986; 61: 2074-2080.

34. Armour CL, Diment LM, Black JL. Relationship between smooth muscle volume and contractile response in airway tissue. Isometric versus isotonic measurement. J Pharmacol Exp Ther 1988; 245: 687-691. 